\title{
The management of psoriasis through diet
}

\author{
This article was published in the following Dove Press journal: \\ Psoriasis: Targets and Therapy \\ I August 2012 \\ Number of times this article has been viewed
}

\author{
Gleison Duarte' \\ Luan Oliveira Barbosa ${ }^{2}$ \\ Maria Elisa A Rosa' \\ 'Dermatology Division, \\ Alergodermoclin, Salvador, \\ Bahia, Brazil; '²scola Bahiana \\ de Medicina e Saúde Pública \\ Salvador, Bahia, Brazil
}

Correspondence: Gleison Duarte Avenida Antônio Carlos Magalhães, 77I-Itaigara, Salvador-BA 41825-000 Brazil

$\mathrm{Tel}+557136166130$

Fax +557136166130

Email gleisonvduarte@yahoo.com.br

\begin{abstract}
Diet is an important factor in the management of several dermatological diseases, such as dermatitis herpetiformis, acne vulgaris, gout, phrynoderma, pellagra, psoriasis, and acrodermatitis enteropathica. New concepts have emerged concerning the influence of diet on psoriasis. For example, diet has an adjuvant role in the management of several cardiovascular comorbidities that exhibit a higher-than-expected prevalence in psoriatic patients. Functional foods, such as yellow saffron and fish oil, may exert favorable effects on immune and cardiovascular functions. A gluten-free diet may promote significant clinical and histologic improvement. Folate supplementation may induce clinical improvement of psoriasis, but side effects may also occur. Diets rich in fresh fruits and vegetables are associated with a lower prevalence of psoriasis, and vegetarian diets were associated with clinical improvement. Additionally, many drug-diet interactions (retinoids, methotrexate, cyclosporine) must be considered in patients with psoriasis. Therefore, in addition to current nutritional advice given to psoriasis patients, further studies are necessary in the role of diet in psoriasis therapy.
\end{abstract}

Keywords: diet, lifestyle, psoriasis, recommendations, supplementation

\section{Introduction}

Diet is an important factor in the management of several dermatological diseases and may also play an important therapeutic role, such as in dermatitis herpetiformis, for which symptoms improve in patients following a gluten-free diet. Other diseases may also be associated with dietary factors, such as atopic dermatitis, acne vulgaris, pemphigus, urticaria and itch. For genetic and metabolic diseases, dietary exclusions or replacements are mandatory (phenylketonuria, tyrosinemia, homocystinuria, galactosemia, Refsum disease, xanthoma, gout, and porphyria). Additionally, disorders due to nutritional deficits, such as kwashiorkor, marasmus, phrynoderma, pellagra, scurvy, and acrodermatitis enteropathica, may also be improved through diet alteration. ${ }^{1,2}$ For decades, dietary and metabolic aspects of psoriasis have been neglected. Because of recent studies examining nutrition and functional aliments, interest in this field of knowledge has increased. An unbalanced diet and intake of unhealthy food was observed in a pilot study performed over two years that included 43 psoriasis patients, $88.37 \%$ of whom exhibited clinical improvement with reduction of scales and erythema after receiving dietary guidance. Additionally, flare-ups were milder, the intervals between flare-ups were longer, and the patients' quality of life improved. Nevertheless, $11.63 \%$ of subjects did not experience improvement. ${ }^{3}$ Ignoring the nutritional value of food, not conciliated meals and work schedules contribute to obesity, nutritional deficit, and worsening of psoriasis. ${ }^{3}$ submit your manuscript $\mid$ www.dovepress.com

Dovepress

http://dx.doi.org// 0.21 47/PTT.S24755
Psoriasis: Targets and Therapy 201 2:2 45-53

(C) 2012 Duarte et al, publisher and licensee Dove Medical Press Ltd. This is an Open Access article which permits unrestricted noncommercial use, provided the original work is properly cited. 
Management of diet and lifestyle may reduce the effect of predisposing factors while simultaneously treating severe comorbidities. ${ }^{4}$ The aim of this paper is to review emerging concepts regarding the connection between diet and psoriasis as well as the role of nutrition in managing psoriasis and associated comorbidities (Table 1).

\section{Role of nutrition in managing psoriasis and associated comorbidities}

Several comorbidities, such as obesity, metabolic syndrome, dyslipidemia, hypertension, atherosclerosis, and diabetes, exhibit a higher than expected prevalence in psoriatic patients. A study performed in the United States showed that $73 \%$ of psoriasis patients exhibited these comorbidities. ${ }^{5,6}$ Therefore, together with standard treatments for the skin affection, treatment of such comorbidities must include management of the diet. ${ }^{4,7}$

Obesity is associated with psoriasis due to the presence of a chronic pro-inflammatory state that promotes several metabolic disorders, contributing to an impaired quality of life and dietary habits of patients. ${ }^{7}$ The relative risk of psoriasis is directly related to body mass index (BMI), and a positive correlation between the Psoriasis Area and Severity Index (PASI) score and BMI has been observed. ${ }^{8,9}$

Fatty tissue acts as an active endocrine tissue and gives rise to a pro-inflammatory state in overweight patients. ${ }^{10}$ The mutual relationship between inflammatory and metabolic responses may have developed because hunger and infection are two primary forces driving species evolution. ${ }^{11}$ Thus, weight loss and obesity control in both murine experimental models and human patients with psoriasis reduces the severity of the disease. ${ }^{10,12}$ In rats, caloric restriction over four weeks decreased cell proliferation by $45 \% .^{13}$
A randomized, placebo-controlled, single-blind clinical trial performed by Gisondi et a ${ }^{14}$ showed that patients treated with cyclosporine and a weight loss diet $(n=30)$ exhibited a better response compared with a group that was not prescribed a diet and did not lose weight $(n=31)$. Only $29 \%$ of patients in the control group achieved the primary outcome (a PASI 75), whereas $66.7 \%$ in the group treated with a low-calorie diet achieved the desired outcome $(P<0.001)$. After 24 weeks, BMI had decreased by $7.0 \% \pm 3.5 \%$ in the intervention group and by only $0.2 \% \pm 0.9 \%$ in the control group $(P<0.001)$. Weight loss induced by low-calorie diets decreases the levels of insulin, leptin, C-reactive protein, and monocyte chemoattractant protein 1 and increases the levels of adiponectin, producing an anti-inflammatory effect that may explain this difference. ${ }^{14}$ That study, however, did not measure the serum levels of cyclosporine, the exposure to which may have increased in patients subjected to a diet who lost weight.

Patients with psoriasis vulgaris treated with topical medications also exhibited a better response to treatment when a low-calorie diet was included as an adjuvant compared with patients who consumed a regular diet, although their body weight was unchanged at the four-week follow-up. ${ }^{15}$

In another study, 33 patients subjected to treatment with immunobiologic agents were assessed for BMI at baseline and after four and eight weeks of treatment. Patients who gained weight by the time of follow-up did not attain a PASI 50, whereas patients with a decreased BMI exhibited a PASI 75 or 90 . The study did not take into account whether the poorer response of obese patients was due to pharmacokinetic alterations at the level of fatty tissue or to the necessity of adjusting doses for body weight or BMI. ${ }^{16}$

In contrast, Esposito et a $\mathrm{l}^{17}$ did not observe an influence of BMI on the criteria of improvement in 100 patients treated with etanercept. ${ }^{17}$

Table I Patterns of the influence of the diet on the management of psoriasis

\begin{tabular}{|c|c|c|}
\hline Pattern & Impact & Reference \\
\hline \multirow[t]{3}{*}{ Fish oil } & Did not show efficacy in reducing symptoms or the global clinical appearance. & Søyland et $\mathrm{al}^{20}$ \\
\hline & Slight clinical improvement. & Collier et $\mathrm{al}^{30}$ \\
\hline & Considerable reduction of itching, erythema and flaking and global decrease in the total affected area. & Bittiner et $\mathrm{al}^{31}$ \\
\hline \multirow[t]{3}{*}{ Low-calorie diet } & Better response to low doses of cyclosporine compared to patients without weight loss. & Gisondi et al $^{14}$ \\
\hline & Better response to topical and immunobiologic treatments. & Bardazzi et al $^{16}$ \\
\hline & & Rucevic et al ${ }^{15}$ \\
\hline Folic acid supplements & Clinical improvement of psoriasis vulgaris without side effects. & Carlesimo et $\mathrm{al}^{54}$ \\
\hline \multirow[t]{2}{*}{ Gluten-free diet } & Significant improvement of PASI score in 30/33 AGA-positive patients. & Michaëlsson et al ${ }^{40}$ \\
\hline & Reduction in dermal Ki67 cells and tissue transglutaminase. & Michaëlsson et $\mathrm{al}^{41}$ \\
\hline \multirow[t]{3}{*}{ Vegetarian diet } & Diets rich in fresh fruits and vegetables are associated with a lower prevalence of psoriasis. & Naldi et al ${ }^{69}$ \\
\hline & & Kavli et al $^{70}$ \\
\hline & $\begin{array}{l}\text { Vegetarian diet contains little arachidonic acid, which decreases the formation of inflammatory } \\
\text { eicosanoids. }\end{array}$ & Araújo et $\mathrm{al}^{72}$ \\
\hline
\end{tabular}

Abbreviations: PASI, Psoriasis Area and Severity Index; AGA, anti-gliadin antibodies. 
Several studies agree that low-calorie diets, with or without weight loss, play an adjuvant role in managing psoriasis. ${ }^{18}$

\section{Emerging concepts in diet and psoriasis: importance of functional foods}

In addition to managing metabolic disorders, the role of functional foods in psoriasis is a topic of much speculation. Foods such as fish oil, cranberries, soybeans, nuts, and chocolate exhibit active biological properties beyond their nutritional properties and promote improvement of several features related to human health.

For instance, according to Eastern medicine, yellow saffron (safflower - Carthamus tinctorius) has immunosuppressive effects due to its anti-inflammatory and immunomodulating actions. ${ }^{19}$

Fish oil supplements may exert favorable effects on immune and cardiovascular functions. Psoriasis is less frequent in Japanese, Norwegian, and Eskimo populations whose diets are rich in fatty acids, such as omega-3 (Figure 1), derived from cold-water fish oil; this contrasts with the higher frequency of psoriasis in populations that consume plant and animal oils typical of Western diets, which are rich in omega-6 (Table 1). ${ }^{20,21}$

Omega-3 competes with arachidonic acid (AA) (Figure 1) at the level of the phospholipid membranes and thus reduces prostaglandin-induced inflammation. Several studies have observed increased levels of AA and leukotrienes in psoriatic plaques compared with areas of normal skin. ${ }^{22}$ Among the fatty acids, omega- 3 exhibits the greatest immunomodulating power. Among omega-3 polyunsaturated fatty acids (PUFAs), those derived from fish oil, such as eicosapentaenoic acid (EPA) (Figure 1) and docosahexaenoic acid (DHA) (Figure 1), are biologically more powerful than alpha-linolenic acid (ALA). EPA competitively inhibits the conversion of AA into prostaglandin E2 (PGE2) and leukotriene B4 (LTB4), causing anti-inflammatory effects. ${ }^{23-26}$

Dietary sources of AA include animal products, such as meat and egg yolk. ALA, EPA, and DHA are the most abundant omega-3 fatty acids administered for treating everyday aliments. ${ }^{25}$

Several autoimmune and inflammatory conditions, including psoriasis, are associated with higher levels of interleukin-1, the pro-inflammatory leukotriene leukotriene $\mathrm{B} 4$, which is produced from omega- 6 fatty acids, ${ }^{27}$ and CD25 (the interleukin-2 receptor), whose levels have been shown to decrease with the use of omega-3 supplements. ${ }^{27,28}$
Although the current literature is conflicting, several studies have demonstrated improvement of lesions, with tolerable adverse effects in most cases. ${ }^{29} \mathrm{~A}$ study involving 145 patients with psoriasis vulgaris and a body surface area (BSA) $>8 \%$ did not find that omega-3 was efficacious for reducing symptoms or the overall clinical appearance of the disease. ${ }^{20}$ Another study which included 18 patients with chronic plaque psoriasis showed that intake of fish oil was associated with a slight clinical improvement and an increase in serum EPA. ${ }^{30}$

Wolters ${ }^{13}$ observed that the results of randomized controlled clinical trials generally report less favorable outcomes; among four studies, only one reported benefits associated with the use of omega-3 fatty acid supplements taken orally, whereas the other three failed to observe benefits compared with a placebo. In a randomized, placebo-controlled, doubleblind clinical trial, 28 patients with stable chronic psoriasis were divided into two groups, one group treated with fish oil and the other group treated with a placebo, and instructed to not modify their usual diets. Eight weeks later, itching, erythema, flaking, and the total affected area had diminished considerably in the treated group, whereas no changes were observed in the control group. ${ }^{31}$

In contrast to the primarily negative results obtained for oral supplements of omega-3 fatty acids, parenteral administration showed improvements. In one study, 20 patients with acute guttate psoriasis and an affected BSA of at least $10 \%$ were randomly divided into two groups which received daily omega-3-based or conventional omega-6-based lipid infusions. Disease severity decreased considerably in all patients in the omega-3 group and moderately in the omega-6 group. ${ }^{32}$

In regard to psoriatic arthritis, only one study found subjective improvement of pain with use of the supplements eicosapentaenoic ethyl ester and docosahexaenoic acid ethyl ester fatty acids, suggesting an adjuvant role of such agents in this condition. ${ }^{33}$

Namazi ${ }^{34}$ studied a population from Western Africa and found a $0.4 \%$ prevalence of psoriasis in Ghana, whereas in the Ukraine, it was $6.2 \%$ during the same period. This difference was attributed not only to genetic factors, but also to the dietary habits of the African population, which is based on corn. Corn contains linoleic acid (LA), a precursor of PGE2. Hyperproduction of PGE2 as an effect of long-term diets based on LA is due to the lack of other PUFAs, such as those found in fish oil; this food contains EPA and DHA, which are responsible for inhibiting conversion of LA into PGE2. The lack of vitamins, including riboflavin, which 


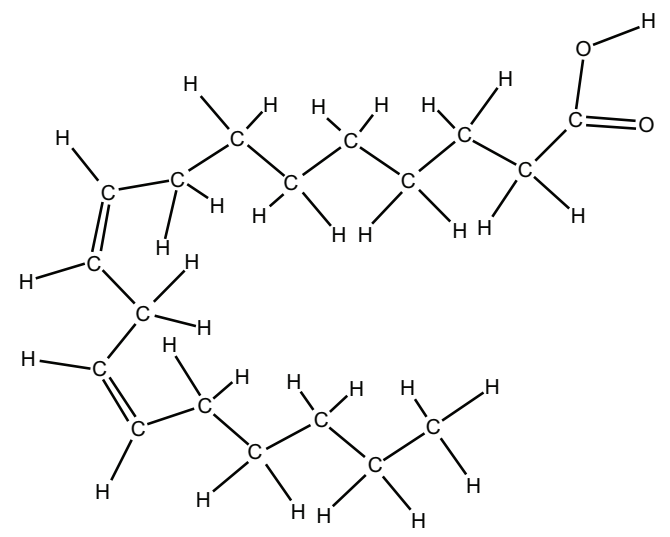

LA, linoleic acid, 18:2 $\omega 6$ (18:2n-6)

(Contains 18 carbon atoms and 2 double bonds or unsaturation sites)

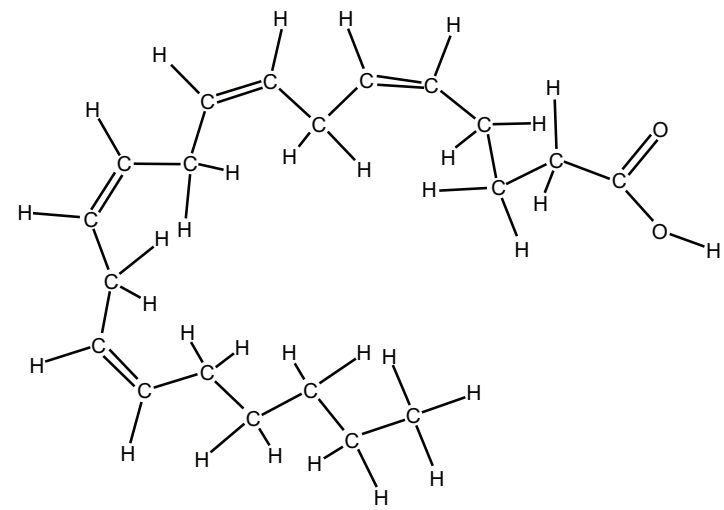

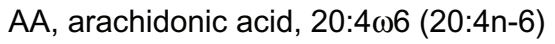

(Contains 20 carbon atoms and 4 double bonds or unsaturation sites)

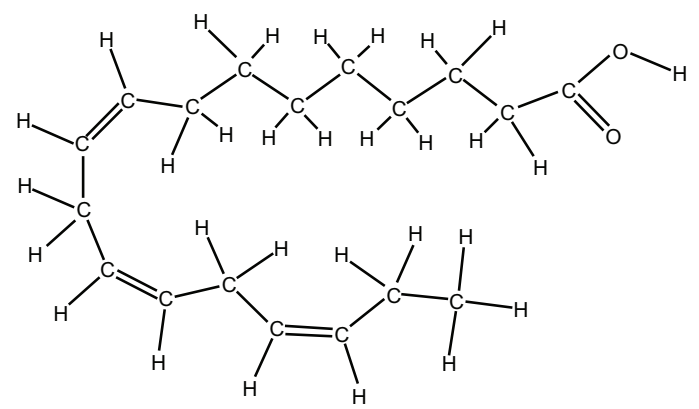

ALA, alpha-linolenic acid, 18:303 (18:3n-3)

(Contains 18 carbon atoms and 3 double bonds or unsaturation sites)

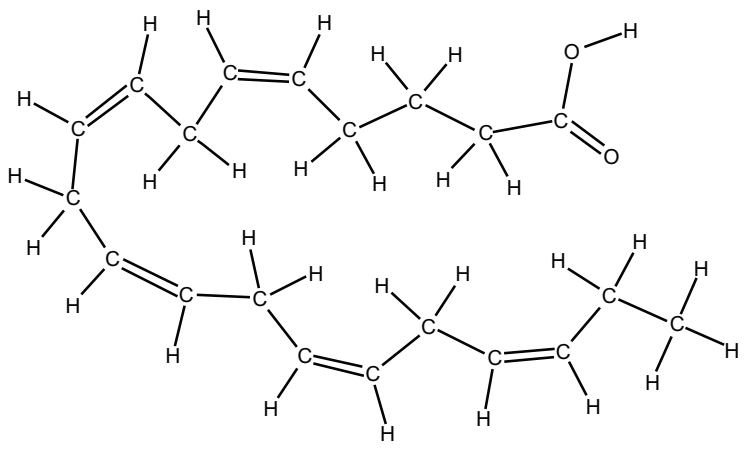

EPA, eicosapentaenoic acid, 20:5 133 (20:5n-3)

(Contains 20 carbon atoms and 5 double bonds or unsaturation sites)

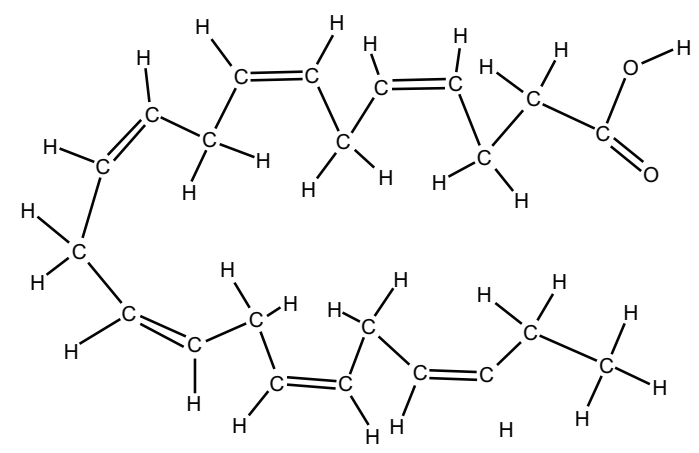

DHA, docosahexanoic acid, 22:6 63 (22:6n-3)

(Contains 22 carbon atoms and 6 double bonds or unsaturation sites)

Figure I Chemical structures of linoleic acid (LA), alpha-linolenic acid (ALA), arachidonic acid (AA), eicosapentaenoic acid (EPA), and docosahexanoic acid (DHA). 
is characteristic of the African diet and contributes to the hyperproduction of PGE2, results in depression of cellular immunity and a reduction in psoriasis. It has been further shown that PUFAs, including LA, directly block $\mathrm{T}$ cell signaling, affecting interleukin-2 and its receptor, and thus decreasing proliferation of T cells. ${ }^{34}$

Diet may play a role in many others immunomodulated diseases, such as Leishmaniasis. Individuals with proteinenergy deficiency appear to produce high levels of PGE2 with consequent immune deficiency, eventually favoring the spread of intracellular parasites such as Leishmania donovani. ${ }^{35}$

Further studies are required to examine the influence of diet on the production of prostaglandins and their pathogenic roles in cellular immunity and inflammation.

\section{Role of a gluten-free diet}

An association was described between celiac disease and several autoimmune diseases and psoriasis. Levels of antibodies (anti-gliadin, anti-endomysial and anti-transglutaminase) correlate with the severity of psoriasis. Additionally, cases have been reported in which psoriasis improved through a gluten-free diet (GFD). ${ }^{36-41}$ This association between celiac disease and psoriasis can be explained by the profile of cytokine release. In psoriasis, most type $1 \mathrm{~T}$ helper (Th1) cells produces interferon-gamma and interleukin-2; in vitro, the $\mathrm{T}$ cells of celiac patients produce a similar cytokine profile in response to gluten. The increase in these cytokines in the serum may trigger celiac disease or reveal an individual predisposition to psoriasis. ${ }^{42}$

Gluten-sensitive enteropathy manifests with few or no gastrointestinal symptoms. In the case of silent celiac disease, antibody tests can be used to identify gluten-sensitive patients; tecidual transglutaminase (tTG) appears to be the predominant autoantigen present in both the bowels and the skin of celiac patients. ${ }^{43-46}$

A study including 123 patients with palmoplantar pustulosis, of whom 113 were female, measured anti-gliadin and anti-tTG IgA antibodies and the effects of a GFD. Initially, $18 \%$ of patients exhibited anti-gliadin and $10 \%$ had anti-tTG antibodies, which reached normal levels accompanied by the complete or nearly complete disappearance of the lesions after adopting a GFD. ${ }^{36}$

In one study, $16 \%$ of patients with psoriasis exhibited anti-gliadin antibodies (AGA). Thirty-three AGA-positive and six AGA-negative patients were subjected to a GFD for three months followed by three months of a normal diet. After the GFD period, 30 out of 33 AGA-positive patients exhibited a highly significant decrease in PASI, and $82 \%$ of those exhibited reductions in AGA levels, whereas AGA-negative patients showed no improvement. When a normal diet was resumed, psoriasis worsened in 18 of 30 AGA-positive patients who completed the GFD period. $^{40}$

Immunohistochemical tests were performed on the skin lesions of 28 AGA-positive psoriasis patients before and after three months of a GFD. Although the pathogenetic role of tTG requires further elucidation, tTG was found to be overexpressed in the skin compared with the papillary epithelium and exhibited a $50 \%$ reduction after the GFD. ${ }^{41}$

Because a large number of undiagnosed patients with gluten intolerance are clinically silent, it is recommended that patients with moderate to severe psoriasis or palmoplantar pustulosis be subjected to autoantibody screening.

\section{Patient-specific considerations - role of zinc, vitamin $D$, and folic acid supplements}

Zinc

Zinc deficiency may be due to flaking of the psoriasiform plaques; however, supplements have not been shown to significantly reduce average PASI scores compared with patients taking placebo. ${ }^{29}$

\section{Folic acid}

The effects of folate supplements on psoriatic patients are not well-known. High homocysteine levels are considered to be an independent risk factor for cardiovascular disease. It is believed that this molecule promotes endothelial dysfunction due to the accumulation of asymmetric dimethylarginine, which is a natural inhibitor of nitric oxide synthase. A reduction in nitric oxide, which protects against thrombosis and atherosclerosis, may increase aortic rigidity and other endothelial damage. High homocysteine and low folate levels in the erythrocytes were previously observed in patients with psoriasis compared to individuals without this condition. ${ }^{47-50}$

The correlation of the levels of these molecules with the severity of psoriasis measured using PASI score highlights the conflicting results in the literature. One study showed that patients with psoriasis $(\mathrm{n}=98)$ exhibited higher homocysteine levels than control subjects $(\mathrm{n}=98)(57 \times 25 \% ; P<0.0001)$. The study found no reduction of folic acid levels in patients, and did not observe a correlation between homocysteine levels and PASI score. ${ }^{51}$ Another study including a smaller 
Table 2 American Heart Association nutrition committee practical recommendations to adhere to a healthy diet ${ }^{81}$

Eat a diet rich in fruit and vegetables

Choose whole-grain, high-fiber foods

Eat fish, particularly oily fish, at least twice a week

Choose lean meat and vegetarian alternatives, use fat-free dairy

products and minimize the intake of partially hydrogenated fat

Avoid drinks and juices with added sugar

Choose and prepare foods with little salt

If you consume alcohol, do so in moderation

sample of 70 participants in each group found no differences in the levels of folic acid or homocysteine; however, a correlation between the PASI score and homocysteine levels was observed in psoriatic patients. ${ }^{52}$ Additionally, obese patients exhibit decreased folate and increased homocysteine levels. $^{53}$

A study examining patients with psoriasis vulgaris and a BSA $>6 \%$ assessed the efficacy of calcium folinate supplementation in 58 patients compared with another group of 58 patients subjected to traditional treatments. Although both groups improved, the group treated with calcium folinate did not exhibit adverse effects. ${ }^{54}$

Folate supplementation must be carefully assessed to determine the cost-benefit ratio; in contrast to other dietary approaches, this supplement may be associated with side effects. Safe daily levels remain unknown but are likely to be approximately $1 \mathrm{mg} /$ day in adults and $300-800 \mu \mathrm{g} / \mathrm{d}$ in children. Serum folate levels $>45 \mathrm{nmol} / \mathrm{L}$ are rated as supraphysiological. In countries in which the fortification of flour is mandatory, such as the United States, Canada, and the United Kingdom, supplementation may cause overexposure to folic acid, and its safety is controversial. Possible adverse effects include reduced efficacy of or resistance to methotrexate, antibiotics, and antimalarial and anti-neoplastic agents, in addition to ambiguous effects on the development of the colon, prostate, and breast cancer. ${ }^{55,56}$

Further evidence is needed before folate supplements can be used for treating patients with psoriasis with cardiovascular risks. ${ }^{55}$

\section{Vitamin D}

In addition to its role in calcium homeostasis and bone metabolism, 1,25-dihydroxyvitamin D3, which is the active form of vitamin $\mathrm{D}$, effects more than 30 different tissues mediated via the vitamin $\mathrm{D}$ receptor. The skin is one such target of 1,25-(OH $)_{2} \mathrm{D}_{3}$ (calcitriol) because keratinocytes express the vitamin D receptor. Calcitriol was shown to inhibit growth and maturation of human keratinocytes in one study. Calcitriol and its analogs exert anti-proliferative and pro-differentiating actions in addition to immunomodulating activities. Vitamin D receptor ligands directly influence $\mathrm{T}$ cell activation and modulate the phenotype and function of antigen-presenting cells. ${ }^{57,58}$ Vitamin D analogs, such as calcipotriene and tacalcitol, are first-line agents used for treating psoriasis..$^{57,59}$

In a double-blind placebo study, vitamin D supplements did not improve psoriasis in patients treated for osteoporosis compared to control subjects. ${ }^{29}$

Vitamin D insufficiency is a general problem. In such cases, oral vitamin D supplements must be considered for patients with psoriasis who do not use topical vitamin D analogs. ${ }^{58}$

\section{Drug-diet interactions}

Drug-diet interactions must also be considered in patients with psoriasis. ${ }^{13}$

Patients using retinoids must avoid diets rich in vitamin A to prevent the risk of hypervitaminosis A, which is characterized by headache, weakness, and anorexia. Retinoids can induce hyperlipidemia and thus require regular monitoring. Triglycerides can be reduced through a diet poor in saturated fatty acids and rich in omega-3 fatty acids. Additionally, the use of alcohol and dietary monosaccharides must be reduced. ${ }^{60-62}$

Severe psoriasis has been associated with nutritional deficiency due to an accelerated loss of nutrients. Approximately $30 \%$ of patients require systemic treatment. In addition, dietary factors may alter the pharmacokinetics and pharmacodynamics of drugs. Methotrexate causes loss of appetite and is contraindicated in patients with poor nutritional status. ${ }^{63-65}$

Grapefruit juice promotes downregulation of the enzyme cytochrome $\mathrm{P} 450$ in the intestinal wall, decreasing the oral bioavailability of cyclosporine by more than $60 \%$. Therefore, patients must be advised to avoid consuming grapefruit juice while using cyclosporine. ${ }^{66-68}$

\section{Recommendations for patients}

In addition to being provided with appropriate guidance, patients with psoriasis must be educated regarding dietary habits to improve their quality of life and increase the effectiveness of adjuvants as pharmacological treatment. ${ }^{3}$ The effects of rich, varied, alcohol-restricted, and low-calorie diets are well-documented in the literature. Naldi et al and Kavli et al demonstrated through epidemiological studies that diets rich in fresh fruits and vegetables are associated with 
a lower prevalence of psoriasis. ${ }^{69,70}$ Additionally, vegetarian and omega-3-rich diets alternating with fasting periods were associated with clinical improvement. ${ }^{13,71}$

In turn, Araújo et al observed that vegetarian diets reduce AA formation, with a consequent decrease in the formation of inflammatory eicosanoids. ${ }^{72}$ Twenty patients with psoriatic arthritis and dermatological diseases were subjected to modified fasting for two weeks followed by a vegetarian diet for three weeks. During the fasting period, patients exhibited improvement that continued during the vegetarian phase. ${ }^{73}$

Intake of fruits and vegetable may benefit the treatment of psoriasis due to the ingestion of antioxidant agents, such as carotenoids, flavonoids, and vitamin C. Antioxidant agents promotes the regulation of oxidative stress and antioxidative defense in psoriasis. Ascorbic acid exhibits hydrophilic antioxidant action, whereas alpha-tocopherol hinders lipid peroxidation from spreading. The antioxidant activity of beta-carotene is due to its ability to sequester free radicals; thus, it is a powerful suppressor of oxygen. Selenium is essential for the function of selenoproteins that participate in antioxidant defense. ${ }^{69,74-77}$

Because obesity is a risk factor for several comorbidities, including psoriasis, and exerts negative influence on psoriasis severity, all patients with psoriasis are recommended to establish healthy habits and active lifestyles. Overweight or obese patients must be subjected to low-calorie diets according to the recommendations of the American Heart Association adopted by the National Psoriasis Foundation to reduce excess weight, which is an independent risk factor for cardiovascular disease (Table 2). ${ }^{78}$

Individuals with insulin resistance also exhibit a higher prevalence of psoriasis compared with the overall population. High glycemic index foods promote insulin resistance and stimulate expression of pro-inflammatory cytokine genes, with a consequent theoretical risk of triggering or worsening psoriasis. This risk was confirmed by Boencke et al who found a positive correlation between PASI score and insulin levels. Thus, the inclusion of low glycemic index foods may become a part of the general management of psoriatic patients because they decrease the risk of serious cardiovascular comorbidities and indirectly promote improvement of the disease. $^{79,80}$

\section{Conclusion}

Despite the relevance of diet in treating dermatological diseases, only changing nutritional habits does not replace conventional treatment, but must be considered as an adjuvant.
Further studies are needed to compare the effects of diet combined with systemic treatments, as well as the benefits of different types of diets, nutritional supplements, and restrictions.

Individual and cultural features, habits, and medical histories make it difficult to standardize and assess the efficacy of diet in psoriasis. Problems with isolating other variables, such as spontaneous remissions, the use of parallel medications, or the removal of other triggers, make such inferences even more difficult.

Although the long-term impact of weight loss and lowcalorie diets has not yet been soundly established through controlled trials, it is safe to recommend these measures to patients with excess weight.

Until consistent evidence is developed, omega-3 supplements can be replaced by instructions to consume fish rich in PUFAs; gluten must be excluded only for patients with positive autoantibodies, and vitamin supplements must be assessed on an individual basis.

\section{Disclosure}

The authors report no conflict of interest in this work.

\section{References}

1. Kaimal S, Thappa DM. Diet in dermatology: revisited. Indian J Dermatol Venereol Leprol. 2010;76(2):103-115.

2. Rackett SC, Rothe MJ, Grant-Kels JM. Diet and dermatology. The role of dietary manipulation in the prevention and treatment of cutaneous disorders. J Am Acad Dermatol. 1993;29(3):447-461.

3. Festugato M. Estudo piloto sobre alimentos que devem ser evitados nos portadores de psoríase [Pilot study on foods that must be avoided by psoriatic patients]. An Bras Dermatol. 2011;86(6):1103-1108.

4. Treloar V. Integrative dermatology for psoriasis: facts and controversies Clin Dermatol. 2010;28(1):93-99.

5. Pearce DJ, Morrison AE, Higgins KB, et al. The comorbid state of psoriasis patients in a university dermatology practice. $J$ Dermatolog Treat. 2005;16(5-6):319-323.

6. Puig-Sanz L. La psoriasis, ¿una enfermedad sistémica? Actas Dermosifiliogr. 2007;98(6):396-402.

7. Duarte GV, Follador I, Cavalheiro CM, Silva TS, Oliveira Mde F. Psoriasis and obesity: literature review and recommendations for management. An Bras Dermatol. 2010;85(3):355-360.

8. Duarte GV, Oliveira MFSP, Cardoso TM. 2012. In press.

9. Naldi L, Chatenoud L, Linder D, et al. Cigarette smoking, body mass index, and stressful life events as risk factors for psoriasis: results from an Italian case-contrel study. J Invest Dermatol 2005; 125(1):61-67.

10. Hamminga EA, van der Lely AJ, Neumann HA, Thio HB. Chronic inflammation in psoriasis and obesity: implications for therapy. Med Hypotheses, 2006;67(4):768-773.

11. Jullien D. Physiopathologie du syndrome métabolique [Physiopathology of the metabolic syndrome]. Ann Dermatol Venereol. 2008;135(4):S243-S248.

12. de Menezes Ettinger JE, Azaro E, de Souza CA, et al. Remission of psoriasis after open gastric bypass. Obes Surg. 2006;16(1):94-97.

13. Wolters M. Diet and psoriasis: experimental data and clinical evidence. Br J Dermatol. 2005;153(4):706-714. 
14. Gisondi P, Del Giglio M, Di Francesco V, Zamboni M, Girolomoni G. Weight loss improves the response of obese patients with moderateto-severe chronic plaque psoriasis to low-dose cyclosporine therapy: a randomized, controlled, investigator-blinded clinical trial. Am J Clin Nutr. 2008;88(5):1242-1247.

15. Rucević I, Perl A, Barisić-Drusko V, Adam-Perl M. The role of the low energy diet in psoriasis vulgaris treatment. Coll Antropol. 2003;27(Suppl 1):41-48.

16. Bardazzi F, Balestri R, Balde E, Antonucci A, De Tommaso S, Patrizi A. Correlation between BMI and PASI score in patients affected by moderate to severe psoriasis undergoing biological therapy. Dermatol Ther. 2010;23(Supp1 1):S14-S19.

17. Esposito M, Mazzotta A, Saraceno R, Schipani C, Chimenti S. Influence and variation of the body mass index in patients treated with etanercept for plaque-type psoriasis. Int J Immunopathol Pharmacol. 2009;22(1):219-225.

18. Farías MM, Serrano V, de la Cruz C. Psoriasis y obesidad: revisión y recomendaciones prácticas [Psoriasis and obesity: review and practical recommendations]. Actas Dermosifiliogr. 2011;102(7):505-509.

19. Lu ZW, Liu F, Hu J, Bian D, Li FG. Suppressive effects of safflower yellow on immune functions. Zhongguo Yao Li Xue Bao. 1991;12(6):537-542.

20. Søyland E, Funk J, Rajka G, et al. Effect of dietary supplementation with very-long-chain n-3 fatty acids in patients with psoriasis. $N \mathrm{Engl}$ $J$ Med. 1993;328(25):1812-1816.

21. Logan AC. Omega-3, omega-6 and psoriasis: a different view. Int $J$ Dermatol. 2005;44:524-525.

22. Voorhees JJ. Leukotrienes and other lipoxygenase products in the pathogenesis and therapy of psoriasis and other dermatoses. Arch Dermatol. 1983;119(7):541-547.

23. Grimminger F, Mayser P. Lipid mediators, free fatty acids and psoriasis. Prostaglandins Leukot Essent Fatty Acids. 1995;52(1):1-15.

24. James MJ, Gibson RA, Cleland LG. Dietary polyunsaturated fatty acids and inflammatory mediator production. Am JClin Nutr. 2000;71(Suppl 1): 343S-348S.

25. Jones PJH, Papamandjaris AA. Lipids: cellular metabolism. In: Bowman BA, Russell RM, editors. Present Knowledge in Nutrition. Washington, DC: ILSI Press; 2001:104-114.

26. Holub BJ. Clinical nutrition: 4 . Omega-3 fatty acids in cardiovascular care. CMAJ. 2002;166(5):608-615.

27. Simopoulos AP. Omega-3 fatty acids in inflammation and autoimmune diseases. J Am Coll Nutr. 2002;21(6):495-505.

28. Søyland E, Lea T, Sandstad B, Drevon A. Dietary supplementation with very long-chain n-3 fatty acids in man decreases expression of the interleukin-2 receptor (CD25) on mitogen-stimulated lymphocytes from patients with inflammatory skin diseases. Eur J Clin Invest. 1994;24(4):236-242.

29. Smith N, Weymann BA, Tausk FA, Gelfand JM. Complementary and alternative medicine for psoriasis. A qualitative review of the clinical trial literature. J Am Acad Dermatol. 2009;60(5): 841-856.

30. Collier PM, Ursell A, Zaremba K, Payne CM, Staughton RC, Sanders T. Effect of regular consumption of oily fish compared with white fish on chronic plaque psoriasis. Eur J Clin Nutr. 1993;47(4): 251-254.

31. Bittiner SB, Tucker WF, Cartwright I, Bleehen SS. A doubleblind, randomised, placebo-controlled trial of fish oil in psoriasis. Lancet. 1988;1(8582):378-380.

32. Grimminger F, Mayser P, Papavassilis C, et al. A double-blind, randomized, placebo-controlled trial of n-3 fatty acid based lipid infusion in acute, extended guttate psoriasis. Rapid improvement of clinical manifestations and changes in neutrophil leukotriene profile. Clin Invest. 1993;71(8):634-643.

33. Lassus A, Dahlgren AL, Halpern MJ, Santalahti J, Happonen HP. Effects of dietary supplementation with polyunsaturated ethyl ester lipids (Angiosan) in patients with psoriasis and psoriatic arthritis. J Int Med Res. 1990;18(1):68-73.
34. Namazi MR. Why is psoriasis uncommon in Africans? The influence of dietary factors on the expression of psoriasis. Int $J$ Dermatol. 2004;43(5):391-392.

35. Anstead GM, Chandrasekar B, Zhao W, Yang J, Perez LE, Melby PC. Malnutrition alters the innate immune response and increases early visceralization following Leishmania donovani infection. Infect Immun. 2001;69(8):4709-4718.

36. Michaëlsson G, Kristjánsson G, Pihl Lundin I, Hagforsen E. Palmoplantar pustulosis and gluten sensitivity: a study of serum antibodies against gliadin and tissue transglutaminase, the duodenal mucosa and effects of gluten-free diet. Br J Dermatol. 2007;156(4):659-666.

37. Ojetti V, Aguilar Sanchez J, Guerriero C, et al. High prevalence of celiac disease in psoriasis. Am J Gastroenterol. 2003;98(11):2574-2575.

38. Calderón HP, Valdés AP, Zemelman DV, et al. Frequency of celiac disease among patients with psoriasis. Rev Med Chil. 2007;135(10): 1296-1303.

39. Birkenfeld S, Dreiher J, Weitzman D, Cohen AD. Coeliac disease associated with psoriasis. Br J Dermatol. 2009;161(6):1331-1334.

40. Michaëlsson G, Gerdén B, Hagforsen E, et al. Psoriasis patients with antibodies to gliadin can be improved by a gluten-free diet. $\mathrm{Br} J \mathrm{Der}$ matol. 2000;142(1):44-51.

41. Michaëlsson G, Ahs S, Hammarström I, Lundin IP, Hagforsen E. Gluten-free diet in psoriasis patients with antibodies to gliadin results in decreased expression of tissue transglutaminase and fewer Ki67+ cells in the dermis. Acta Derm Venereol. 2003;83:425-429.

42. Chalmers RJG, Kirby B. Gluten and psoriasis. $\mathrm{Br} J$ Dermatol. 2000;142:5-7.

43. Michaëlsson G, Gerdén B, Ottosson M, et al. Patients with psoriasis often have increased serum levels of IgA antibodies to gliadin. Br J Dermatol. 1993;129:667-673.

44. Nelson DA. Gluten-sensitive enteropathy (celiac disease): more common than you think. Am Fam Physician. 2002;66:2259-2266.

45. Leffler D, Saha S, Farrell RJ. Celiac disease. Am J Manag Care. 2003;9:825-831.

46. Duggan JM. Coeliac disease: the great imitator. Med J Aust. 2004;180:524-526.

47. Malerba M, Gisondi P, Radaeli A, Sala R, Pinton PG, Girolomoni G. Plasma homocystein and folate levels in patients with chronic plaque psoriasis. Br J Dermatol. 2006;155:1165-1169.

48. Kural BV, Orem A, Cimsit G, Uydu HA, Yandi YE, Alver A. Plasma homocysteine and its relationships with atherothrombotic markers in psoriasis patients. Clin Chim Acta. 2003;332:23-30.

49. Fry L, Macdonald A, Almeyda J, Griffin CJ, Hoffbrand AV. The mechanism of folate deficiency in psoriasis. $\mathrm{Br} J$ Dermatol. 1971;84:539-544.

50. Karabudak O, Ulusoy RE, Erikci AA, Solmazgul E, Dogan B, Harmanyeri Y. Inflammation and hypercoagulable state in adult psoriatic men. Acta Derm Venereol. 2008;88(4):337-340.

51. Brazzelli V, Grasso V, Fornara L, et al. Homocysteine, vitamin B12 and folic acid levels in psoriatic patients and correlation with disease severity. Int J Immunopathol Pharmacol. 2010;23(3):911-916.

52. Cakmak SK, Gül U, Kiliç C, Gönül M, Soylu S, Kiliç A. Homocysteine, vitamin B12 and folic acid levels in psoriasis patients. J Eur Acad Dermatol Venereol. 2009;23(3):300-303.

53. Tobin AM, Hughes R, Hand EB, Leong T, Graham IM, Kirby B. Homocysteine status and cardiovascular risk factors in patients with psoriasis: a case-control study. Clin Exp Dermatol. 2011;36(1):19-23.

54. Carlesimo M, Mari E, Arcese A, et al. Safety and efficacy of calcium folinate in psoriasis: an observational study. Int $J$ Immunopathol Pharmacol. 2010;23(2):649-653.

55. Gisondi P, Fantuzzi F, Malerba M, Girolomoni G. Folic acid in general medicine and dermatology. J Dermatolog Treat. 2007; 18(3):138-146.

56. Smith AD, Kim YI, Refsum H. Is folic acid good for everyone? Am J Clin Nutr. 2008;87(3):517-533.

57. Holick MF. Vitamin D: a millennium perspective. J Cell Biochem. 2003;88:296-307. 
58. Adorini L. Immunomodulatory effects of vitamin D receptor ligands in autoimmune diseases. Int Immunopharmacol. 2002;2:1017-1028.

59. Pinette KV, Yee YK, Amegadzie BY, Nagpal S. Vitamin D receptor as a drug discovery target. Mini Rev Med Chem. 2003;3:193-204.

60. Simopoulos AP. Omega-3 fatty acids in health and disease and in growth and development. Am J Clin Nutr. 1991;54:438-463.

61. Hellerstein MK. Carbohydrate-induced hypertriglyceridemia: modifying factors and implications for cardiovascular risk. Curr Opin Lipidol. 2002;13:33-40.

62. Parks EJ, Parks EJ. Changes in fat synthesis influenced by dietary macronutrient content. Proc Nutr Soc. 2002;61:281-286.

63. Prystowsky JH, Orologa A, Taylor S. Update on nutrition and psoriasis. Int J Dermatol. 1993;32:582-586.

64. Peckham PE, Weinstein GD, McCullough JL. The treatment of severe psoriasis: a national survey. Arch Dermatol. 1987;123:1303-1307.

65. Lebwohl M. The role of salicylic acid in the treatment of psoriasis. Int J Dermatol. 1999;38:16-24.

66. Brown RO, Dickerson RN. Drug-nutrient interactions. Am J Manag Care. 1999;5:345-355.

67. Dahan A, Altman H. Food-drug interaction: grapefruit juice augments drug bioavailability - mechanism, extent and relevance. Eur J Clin Nutr. 2004;58:1-9.

68. Ducharme MP, Provenzano R, Dehoorne-Smith M, Edwards DJ. Trough concentrations of cyclosporine in blood following administration with grapefruit juice. Br J Clin Pharmacol. 1993;36:457-459.

69. Naldi L, Parazzini F, Peli L, et al. Dietary factors and the risk of psoriasis. Results of an Italian case-control study. $\mathrm{Br} J$ Dermatol. 1996;134:101-106.

70. Kavli G, Forde OH, Arnesen E, Stenvold SE. Psoriasis: familial predisposition and environ-mental factors. $\mathrm{Br} \mathrm{Med} \mathrm{J} \mathrm{(Clin} \mathrm{Res} \mathrm{Ed).}$ 1985;291:999-1000.
71. Wolters M. The significance of diet and associated factors in psoriasis. Hautarzt. 2006;57(11):999-1004.

72. Araujo ML, Burgos MG, Moura IS. Nutritional influences in psoriasis. An Bras Dermatol. 2009;84(1):90-92.

73. Lithell H, Bruce A, Gustafsson IB, et al. A fasting and vegetarian diet treatment trial on chronic inflammatory disorders. Acta Derm Venereol (Stockh). 1983;63:397-403.

74. Frei B. On the role of vitamin $\mathrm{C}$ and other antioxidants in atherogenesis and vascular dysfunction. Proc Soc Exp Biol Med. 1999;222:196-204.

75. Kaul N, Devaraj S, Jialal I. Alpha-tocopherol and atherosclerosis. Exp Biol Med (Maywood). 2001;226:5-12.

76. Bendich A. From 1989 to 2001: what have we learned about the 'biological actions of beta-carotene'? J Nutr. 2004;134:S225-S230.

77. Burk RF, Levander OA. Selenium. In: Shils ME, Olson JA, Shike M, Ross AC, editors. Modern Nutrition in Health and Disease. 9th ed. Baltimore: Williams \& Wilkins; 1999:265-276.

78. Kimball A, Gladman D, Gelfand J, et al. National Psoriasis Foundation clinical consensus on psoriasis comorbidities and recommendations for screening. J Am Acad Dermatol. 2008;58:1031-1042.

79. Boehncke S, Thaci D, Beschmann H, et al. Psoriasis patients show signs of insulin resistance. Br J Dermatol. 2007;157(6):1249-1251.

80. Reynoso-von Drateln C, Martínez-Abundis E, Balcázar-Muñoz BR, Bustos-Saldaña R, González-Ortiz M. Lipid profile, insulin secretion, and insulin sensitivity in psoriasis. J Am Acad Dermatol. 2003 48(6):882-885.

81. American Heart Association website available at http://www.heart.org/ HEARTORG/. Accessed July 1, 2012.
Psoriasis: Targets and Therapy

\section{Publish your work in this journal}

Psoriasis: Targets and Therapy is an international, peer-reviewed, open access journal focusing on psoriasis, nail psoriasis, psoriatic arthritis and related conditions, identification of therapeutic targets and the optimal use of integrated treatment interventions to achieve improved outcomes

\section{Dovepress}

and quality of life. Visit http://www.dovepress.com/testimonials.php to read real quotes from published authors. 